\title{
The Effects of One-One Instructions on Grade Equivalence Scores of Emergent Readers
}

\author{
Yvonne, J. John ${ }^{1} \&$ Elna, C. Carrington-Blaides ${ }^{2}$ \\ ${ }^{1}$ Special Needs Education, The University of Trinidad and Tobago, Valsayn, Trinidad and Tobago \\ ${ }^{2}$ M.Ed. Inclusive and Special Education, University of the West Indies, St. Augustine, Trinidad and Tobago \\ Correspondence: Yvonne, J. John, Ph.D, 50 Mora Drive, Homeland Gardens, Cunupia, Trinidad and Tobago. Tel: \\ $1-868-721-2458$
}

Received: June 10, 2015 Accepted: June 25, 2015 Online Published: July 2, 2015

doi:10.5430/ijelt.v2n2p59 URL: http://dx.doi.org/10.5430/ijelt.v2n2p59

\begin{abstract}
This study analyzed the implementation of Tier 3, Response to Intervention (RTI) strategies on Infants 1 - Standard 3 reading scores. The purpose was to determine if students increased their reading abilities after receiving direct, one-one, intense instruction in comparison to students that did not receive the intervention. The study group consisted of 54 primary school students in Infants 1 to Standard 3 grade level in Trinidad and Tobago. The study used an experimental design approach that sought to determine whether the UTT program of reading intervention had the intended causal effect on the program participants. The three key components of the experimental study design: (1) pre-post test design, utilizing the DRA2 ${ }^{\circledR}$ assessment tool before the intervention and after implementation. (2) A control group - Group X who received Tier 1 instructional strategies only, and a treatment group - Group Y, who received Tier 1 core instructions along with Tier 3 one-one direct instructions in reading. (3) Random assignment of study participants to groups $\mathrm{X}$ or $\mathrm{Y}$ followed, after screening. Findings of the study showed that there was a significant difference between students receiving additional Tier 3 instructions when compared to students receiving Tier 1 instruction, based on the pupils’ DRA2 ${ }^{\circledR}$ Reading scores.
\end{abstract}

Keywords: Response to Intervention (RTI), one-one tutoring, DRA2 $®$

\section{Introduction}

Forty-six percent of the students in the primary schools of Trinidad and Tobago are experiencing difficulty to read and comprehend (National Test, 2013). All schools should produce successful readers by providing students instruction that meets their needs. Pupils in the Standard 1 and 3 in Trinidad and Tobago are assessed annually using the National Test in Reading and Mathematics. If students' score at/or below the 30th percentile in the Reading assessment, they are considered to be at-risk. Students with similar reading scores are given a variation of support through an MOE assigned reading coach during the school day. Some students receive small group interventions while other students participate in the whole-group instruction.

According to Stern Center for Language and Learning, Response to Intervention/Instruction (RTI) is a multi-tiered method to help all learners succeed. Student progress is closely monitored at each stage of the intervention to determine the need for further research-based instruction and/or intervention in general education, in special education, or both. (http://www.sterncenter.org/resources/RTI, n.d.)

"Research has shown that most reading problems can be prevented by providing high-quality early literacy instruction in the classroom, along with a supplemental intervention for students who need it including those with significant learning disabilities such as dyslexia. The heart of any RTI model lies in the use of tiered instruction. In the RTI framework, the instruction delivered to students varies on several dimensions related to the nature and severity of a student's difficulties". (http://www.sterncenter.org/resources/RTI, n.d.)

\section{Literature Review}

The 2004 Individuals with Disabilities Education Improvement Act (IDEA) provided the option for local education 
agencies (LEAs) to determine the responsiveness of students to scientific research-based interventions as part of the overall student evaluation process. In this context, Response to Intervention (RTI) is both a diagnostic tool and an instructional classroom model as well. Although, variability exists in how proponents and practitioners conceptualize and implement RTI the fundamental characteristics are a basic primary level, tier 1 where every student receives instruction that is research-based in the general education classroom. Secondary level, Tier 2 where students receive research-based focused instruction in small groups. Tertiary level, Tier 3 research-based instructions is focused and direct to individual students and small groups. (Torgesen, 2007; Bradley, Danielson, \& Doolittle, 2005).

\subsection{One-one Tutoring}

Using the RTI model to guide early reading instruction, one-one tutoring is particularly relevant to the evidenced-based instruction at the Tier 3 level of intervention. Tier 3 is characterized by individualized and small group teaching (Barnes, \& Harlacher, 2008). The National Reading Panel (National Institute of Child Health and Human Development, 2000) outlined five areas of reading skill development: phonics, phonemic awareness, text comprehension strategies, vocabulary instruction, and reading fluency. Empirical research has validated one- one instruction programs as the most efficient strategy for improving the performance of students in general. (Bloom, 1984; Cohen, Kulik \& Kulik, 1982; Juel, 1998) noted the link between parents' dissatisfaction with the unacceptable academic progress of their children and the hiring of one-to-one tutors.

One-one instruction programs evolved in significant ways. Prior to the 1970s tutoring programs utilized mainly regular school teachers and professional tutors (Clay, 1985 and Cohen, Kulik \& Kulik, 1982) and subsequently, today older students, paraprofessionals and peers tutor students in modern programs. Although, students tutored outperformed untutored students concerns persisted about the reading level of young and emergent readers (Karweit $\&$ Wasik, 1992). One-one programs facilitated by trained volunteers, college students, and/or paraprofessionals were highly effective (Invernizzi, Juel \& Rosemary, 1997). The major challenge to tutoring is the associated cost. The argument made is that schools should implement successful early intervention programs to avert costly large-scale programs.

\subsection{One-one Programs}

Wasik and Slavin, (1993) reviewed five one-one reading programs, characteristics describing the tutors and tutoring methods/curriculum are noted.

1. Reading Recovery - certified reading teachers are employed. Students receive a half-hour individualized tutoring each day for 12 to 20 weeks with a teacher who is specially trained in Reading Recovery methods.

2. Success for All used certified teachers. Teaching is integrated with structured classroom curriculum while the emphasis is on students using metacognitive strategies.

3. Prevention of Learning Disabilities - Certified teachers are used. The program used directed activities to teach specific perceptual and spatial skills involved in reading. While the emphasis is on skill acquisition, no emphasis is placed on reading connected texts.

4. Wallach Tutoring Program - paraprofessionals are used. This program is a phonics-based tutoring program. It does not focus on reading connected to the text, and it does not integrate with classroom instruction. Emphasis is on systematic mastery of phonics skills.

5. Programmed Tutorial Reading materials - paraprofessionals are used. This program integrates with classroom instructions. The lessons are highly detailed and prescribed. Emphasis is on students developing skills.

Overall the effect sizes of the five tutoring programs were positive with unusually high results recorded for low-performing students. Those tutoring programs that addressed more components of reading were more effective than those that addressed fewer elements of the reading process. Both Reading Recovery and Success for All focused on several components of the reading process. Variables such as the content of the program and the delivery of the program affect the effectiveness of the program. When certified teachers, as opposed to paraprofessionals, were used, substantially better results were obtained.

\subsection{Instructional Skill Focus}

Application of RTI in focused skill areas has support in empirical research. Elbaum et al. (2000) in their meta-analysis of intervention research identified the 'primary focus area of instruction' as a variable. The skill areas were decoding-word recognition, comprehension, mixed phonemic awareness, phonics, and visual perceptual skills. Elbaum et al. contended that the focus of instruction was effect size variation. The skill area related to the greatest effect on reading was reading comprehension, derived largely from direct instruction strategies. A focus on phonemic 
awareness or a mixed focus had a moderate effect on learning while a focus on visual-perceptual skills had no significant effect on learning.

\section{Practice under Investigation}

The practice under investigation is the ability or lack thereof, of teachers in Trinidad and Tobago to appropriately assess and improve reading in primary schools. The National Test of Ministry of Education (MOE) of the Government of the Republic of Trinidad and Tobago (GORTT) is given yearly to the standard one and three students. The data from this national test, show that approximately fifty percent of the students in the five hundred and thirty-seven primary schools are failing to read on grade level. This research highlights the experience of UTT prospective teachers in both assessing and improving reading in primary schools.

\section{Tiered Instruction}

The concept of tiered instruction provides a new opportunity for schools to differentiate instruction to meet the needs of all students. (Walpole \& McKenna, 2012). Small-group and intense one-one, differentiated instruction enhances comprehension skills. "In differentiated classrooms, all students are engaged in instruction and participating in their learning.

Students know that learning is a process, and they know their strengths and areas in need of improvement" (Anderson \& Algozzine, 2007, p. 52). RTI is a way to differentiate instruction in schools. It provides early intervention to students at risk for failure (Fuchs \& Fuchs, 2006).

Through the RTI model, students receive high-quality instruction that matches their needs in a tiered model of support, frequent monitoring of progress, and data-based decision making (Sansosti, Telzrow, \& Noltemeyer, 2010).

Tier 1: Instruction at this level is the whole group and the major goal is "preventative" in general (Berkeley et al., 2009). Interventions consist of the core instruction as dictated in the curriculum. Approximately $80-90 \%$ of students meet benchmark levels of intervention without the need for more intense intervention. Only students who are unresponsive (did not meet established criteria) proceed to Tier 2. Responsive students (met established criteria) remain in the whole group setting for further instruction (Mc Kenzie, 2009).

Tier 2: Interventions are also to the general curriculum. The instruction at this level is the small group. Secondary intervention takes place, students are provided with more intense, supplemental instruction (Berkeley et al., 2009). Considerable variability exists in group size, intensity and duration. Approximately 5-10\% of students in a school are expected to be in this category. Groups are at students' instructional levels.

Tier 3 represents the most intensive level of instruction and intervention and target students' skill deficits. Instruction can be the small group or individualized, approximately $1-5 \%$ of the general education population require instruction at this level. Activities at this tier have comparatively generated the most debate about the role of special education (Berkeley et al., 2009; Mack, Smith, \& Straight, 2010; Mastropieri \& Scruggs, 2005).

\section{Statement of the Problem}

In Trinidad and Tobago, there is no evidence available, relating reading scores to differentiated strategies used by teachers, as measured by assessment tools. Literacy coaches assigned to schools that are considered low performing, determined by the National Test (MOE, n.d.), provide small group instructional services to students considered at-risk for reading failure. No official assessment program is in place to diagnose the needs of these pupils; hence, a direct, explicit and systematic approach is not done to meet better the needs of at-risk readers.

Additionally, Trinidad and Tobago is in the beginning stages of implementing a new curriculum (MOE, 2013). The five crucial principles that guide this curriculum are literacy and numeracy across the curriculum, assessment of learning, differentiation and integration of Information and Communication Technologies. However, classroom teachers and literacy coaches have not been adequately trained to use these principles appropriately to effect meaningful change.

\section{Research Questions}

Question $1(\mathrm{Q} 1)$ : Is there a significant difference between student grade-level equivalent gain for at-risk students 
participating in the UTT's intervention measured by the Developmental Reading Assessment (DRA2 $\left.{ }^{\circledR}\right)$ ?

Question 2 (Q2): Is there a significant difference between student grade-level equivalent gain for at-risk students participating in the UTT's intervention program, when compared with students not participating in the UTT's intervention program, as measured by the Developmental Reading Assessment (DRA2 $\left.{ }^{\circledR}\right)$ ?

\section{Null Hypotheses}

$\mathrm{H}_{1}$ : There is no significant difference between student grade-level equivalent gain for at-risk students participating in the UTT program as measured by the DRA2® pre-test, compared to students who did not receive the UTT program intervention, in December 2014.

$\mathrm{H}_{2}$ : There is no significant difference between student grade-level equivalent gain for at-risk students participating in the UTT program compared to students not participating in the UTT program as measured by the DRA2 ${ }^{\circledR}$ post-test, in April 2015.

\section{Definition of Terms}

\subsection{UTT Intervention}

A program created by UTT SPED department coordinator to provide primary school prospective teachers with a tool that will benefit at-risk readers with adaptive, personalized paths for mastery of essential reading concepts.

\subsection{Developmental Reading Assessment}

The Developmental Reading Assessment K-3 is a research-based and validated assessment program by Joetta Beaver and a team of teachers in the Upper Arlington School District, OH, USA. Primary classroom teachers help pinpoint students' strengths and abilities as readers in a quick, one-on-one conference. DRA2 ${ }^{\circledR}$ for grades K-3, incorporates a fluency component that provides a WPM fluency rate. It streamlines the assessment for easier use and includes several Benchmark Books, a Teacher Guide, a simplified Focus for Instruction, and Continuums to match each assessment text incorporated in the Teacher Observation Guides. In addition, this package also includes Word Analysis to help you assess 40 essential skills in the areas of Phonological Awareness, Meta-language, Letter/Word Recognition, Phonics, and Structural Analysis and Syllabication (Pearson, n.d.).

Table 1. Daily Schedule for RTI instruction

\begin{tabular}{llll}
\hline & Tier 1 & Tier 2 & Tier 3 \\
\hline Instruction Duration & $60-90$ min. daily & $\begin{array}{l}30 \mathrm{~min} . \quad(+ \text { Tier I) } 1-2 \\
\text { rounds }\end{array}$ & 30 min. daily for 10 weeks \\
Group size & Whole Group & $1: 3-5$ & $1: 1$ \\
\hline
\end{tabular}

Students in the experimental group received Tier 1 core instruction with the whole group and an additional 30 minutes daily for 10-12 weeks, in skills-focused instruction.

\section{Research Methodology}

\subsection{Research Design}

This study utilized an experimental design. UTT/UWI researchers conducted an experiment to test a Tier 3 reading intervention, developed to raise the Grade Equivalency Level (GE) of emergent readers. To test the intervention, UTT/UWI researchers screened 300 pupils in Infant 1 - Standard 3 classes in 14 primary schools. The pupils ranged in ages 7 years to 10 years. Fifty-four pupils who were emergent readers were chosen.

Researchers used a randomized approach to assign pupils to treatment and control groups. Researchers also use randomization to assign prospective teacher-tutor to emergent readers.

\subsection{Causation}

9.2.1 Variables Used in the Study.

The independent variables used in the study were Tier 3 instructions implemented with twenty-seven pupils. 
The dependent variables used in the study were Grade Equivalence (GE) obtained in the pre-/post- test processes.

9.2.2 Control

Twenty-seven pupils randomly assigned in the study received Tier 1core instructions in reading, as did all pupils. T-tests will include status of the student indicated as Y: intervention, or an X: no intervention. The dependent variables used in one of the t-test will be students' DRA2 ${ }^{\circledR}$ reading pre-test scores. The dependent variables used in the other t- test will be students' April 2015 DRA2 ${ }^{\circledR}$ reading post-test scores.

\subsection{Sample}

The study group consisted of 54 Infant1- Standard 3 students in schools located in a Trinidad and Tobago (T \& T). Within the study group, students were classified as receiving an intervention and not receiving an intervention. All students were screened using DRA2®. Table 2 illustrates the adjustment made to the original DRA2 ${ }^{\circledR}$ to match $\mathrm{T} \&$ T grade system.

\subsection{Instrumentation Utilized}

Prospective teachers administered the tool to all students in Infants 1 through Standard 3. Using the correlation in Table 2, cut off points for each grade level is determined for where students should score. If students do not score within these ranges, they are automatically placed into RTI - Tier 1, Tier 2 or Tier 3.

Table 2. DRA2 adjusted for Trinidad and Tobago Grade System

GRADE LEVEL Infants 1 Infants 2 Grade Level Standard 1 Grade Levels

\begin{tabular}{|c|c|c|c|c|c|c|c|c|c|c|c|c|c|c|}
\hline Basal Level & \multicolumn{3}{|c|}{ Infant 1} & \multicolumn{2}{|c|}{ Beg. $_{\text {Infant } 2}$} & & \multicolumn{2}{|c|}{ Middle } & \multirow{2}{*}{\multicolumn{2}{|c|}{$\begin{array}{l}\text { End } \\
1416\end{array}$}} & \multirow{2}{*}{$\begin{array}{l}\text { Beg. }{ }_{\text {Std. } 1} \\
18\end{array}$} & \multicolumn{2}{|c|}{ Mid } & End \\
\hline DRA Level & 1 & 2 & 3 & $3-4$ & $5-6$ & 8 & 10 & 12 & & & & 20 & 24 & 28 \\
\hline Guided Reading Level & A & B & $\mathrm{C}$ & $\mathrm{C}$ & $\mathrm{D}$ & E & $\mathrm{F}$ & G & $\mathrm{H}$ & I & $\mathrm{J}$ & $\mathrm{K}$ & $\mathrm{L}$ & $\mathrm{M}$ \\
\hline
\end{tabular}

Guided Reading Levels is a broader range of difficulty in each level for Infant 2. The table shows the adjustment made to the DRA $2 \circledR$ to accommodate the grade equivalence of students in the Trinidad and Tobago grade system.

\subsection{Null Hypotheses}

\subsubsection{Question to Be Investigated}

Is there a significant difference between Grade Equivalence (GE) of students receiving the UTT's intervention compared to the students who did not receive the intervention?

\subsubsection{Hypotheses}

Hypothesis $_{1}$ : There is no significant difference between student grade-level equivalent gain for at-risk students participating in the UTT's intervention program and students not participating in the UTT's intervention program as measured by the DRA2 Reading assessment administered in December 2014.

Hypothesis $_{2}$ : There is no significant difference between student grade-level equivalent gain for at-risk students participating in the UTT's intervention program and students not participating in the UTT's intervention program as measured by the DRA2 Reading assessment administered in April 2015.

\subsection{Data Analysis Strategies}

Two independent t-test analyses of differences between the two groups (students receiving an intervention and students not receiving an intervention) were conducted. Test scores from a pre- test using DRA2 ${ }^{\circledR}$ will be used to determine students' need areas. Test scores from the post- DRA2 ${ }^{\circledR}$ assessment will be used to determine casual effect or lack thereof.

\subsection{Weaknesses in the Study}

Weaknesses in the study include: the small size of the study group; instructional strategies implemented by individual reading teachers outside of the intervention which could also impact scores.

\subsection{Anticipated Benefits of Study}

The benefits of this study will be to know if there is a relationship between at-risk students participating in the Tier 3 
UTT's intervention, and the increase in grade-level equivalency reading scores as measured by the DRA2 $®$ Reading assessment tool. If there is data that shows benefit to having students participate in the UTT's intervention program, it may encourage the MOE of GORTT to use professional development funding for more UTT's intervention (Note 1) program training. Also encourage MOE to use funding to purchase resources for screening and monitoring students' progress in reading in the primary schools. This would enable more at-risk students to show progress in reading.

\section{Results}

\subsection{Problem Statement}

Ministry of Education (MOE) of the Government of the Republic of Trinidad and Tobago (GORTT) does not outfit schools with diagnostic tools to diagnose/prescribe students' needs. Therefore, researchers used eight kits owned by UTT, among fourteen schools, to screen 300 students. This exercise, because of the unavailability of resources at the school site, took a considerable amount of time. Also, not enough information is available to demonstrate the impact the UTT's reading intervention on grade-level equivalent reading levels of at-risk students as measured by the DRA2 ${ }^{\circledR}$ Reading assessment.

\subsection{Analysis Method}

Two independent t-test analyses of the differences between a group of at-risk students receiving the UTT intervention and a group of at-risk students not receiving the UTT intervention were conducted. Students' December 2014 and April 2015 DRA2 $®$ Reading grade-level equivalence scores were used to compare if there are significant differences between students receiving the UTT intervention and students that are not receiving the UTT reading intervention.

\section{Results}

Table 3. T-test comparing Grade Equivalence of Experimental group with Control group in December 2014

\begin{tabular}{llllll}
\hline Grade Equivalence & $\mathrm{N}$ & $\mathrm{t}-\mathrm{cal}$ & $\mathrm{df}$ & $\mathrm{p}$ & Decision \\
\hline $\mathrm{Y}=$ Experimental group & 27 & 0.301213 & 26 & 0.764581 & Accept \\
$\mathrm{X}=$ Control group & 27 & & & & \\
\hline
\end{tabular}

Experimental group participants $\mathrm{Y}$ have similar grade equivalence to control group participants $\mathrm{X}$ in December 2014, $(t(27)=0.301213, \mathrm{p}<.05)$. Therefore researchers accept the null hypothesis for $\mathrm{H}_{1}$.

Table 4. T-test comparing Grade Equivalence of Experimental group with Control group in April 2015

\begin{tabular}{llllll}
\hline Grade Equivalence & $\mathrm{N}$ & $\mathrm{t}$-cal & $\mathrm{df}$ & $\mathrm{P}$ & Decision \\
\hline $\mathrm{Y}=$ Experimental group & 27 & 2.373821 & 26 & 0.021743 & Reject \\
$\mathrm{X}=$ Control group & 27 & & & & \\
\hline
\end{tabular}

Experimental group participants demonstrate significantly higher-grade equivalence (GE) than participants in the control group in April 2015, $(t(27)=2.373821, \mathrm{p}<.05)$. Therefore researchers reject the null hypothesis for Hypothesis $_{2}$. The results show that intense instruction monitoring at Tier 3 level, when instruction matches needs yields significant progress.

\section{Overview, Findings and Recommendations}

\subsection{Overview}

This study analyzed the significance of the UTT intervention program and the impact on a student's DRA2 ${ }^{\circledR}$ reading score when comparing December 2014 and April 2015 data. The study looked at the causal effect of the intervention on at-risk participants.

\subsection{Analysis}

There were no differences in grade equivalence of students receiving UTT intervention, and students not receiving UTT intervention, based on the DRA2®, in December 2014.

Although the subjects had similar abilities, a significant change occurred when an intervention - intense, direct, 
explicit and systematic was implemented with the experimental group versus the control group, in April 2015. The conclusion being that Tier 3 intense treatment designed to match the needs of students made a difference for at-risk readers.

The MOE GORTT has since September of 2014 introduced a new curriculum in its Primary schools. The curriculum is thematic and integrative and has as its five crucial principles - literacy across the curriculum, numeracy across the curriculum, differentiated instruction, assessment of learning and integration of Information and Communication Technologies (ICT) (MOE, 2013). The MOE echoes that the ultimate goal of reading is to assist students in becoming strategic and critical readers, to empower them to achieve independence in reading and use literacy as a tool for life-long learning.

The aim of this study is to demonstrate to the MOE GORTT that assessment prior to and during differentiation of instruction is key to successful implementation of their curriculum. Invernizzi and Quellette (2001) found that programs are most successful when assessment and evaluation guide the implementation process. This research project illustrates that when children are assessed at the outset of the program to identify individual literacy needs and intensely and bi-weekly, to adjust the pace and content of instruction, significant improvement occurs. The researchers, here and via documented literature demonstrate that all instruction should be driven by student assessment and should be on the child's instructional level.

Results of this study and other scheduled replicated studies like this, point to the fact that the Ministry of Education of Trinidad and Tobago (MOETT) should make available to schools the funding needed to acquire assessment tools, appropriate for determining the instructional levels of students. Many principals and teachers in schools chosen as experimental sites expressed the desire to acquire these tools. Of great priority would be the professional development to empower the teachers to use these tools appropriately and effectively. It is the hope that as UTT continues to implement these intervention programs in the schools of Trinidad and Tobago, more principals and teachers will be encouraged by the results demonstrated, and will clamour for the use of appropriate tools and professional development, which can be administered manually or via the integration of ICT.

\subsection{Recommendations That Have Emerged from This Research}

1) MOETT should make decisions to fund schools to acquire appropriate tools for assessment in reading.

2) MOETT's decisions to integrate ICT must incorporate integration of assessment tools such as the DRA2 ${ }^{\circledR}$ PLUS. Integration of assessment tools with ICT enables the process; it makes assessment and alignment to students' instructional levels, quick and accurate, when incorporated with curriculum based management systems.

3) MOETT can prioritize professional development geared to assessment and differentiation of reading instructions during July-August breaks.

4) Students identified as reading below grade-level need to be assessed and receive intense, skills-focused, Tier 3 reading instructions.

5) Response to Intervention process can help teachers to differentiated instruction as it provides instruction to Tier 1 - whole group, Tier 2 - small group and Tier 3 -at-risk students in a class.

6) Over time, differentiated reading interventions will help improve students' reading levels.

Finally, further research into RTI and its potential to impact on the education system in assessment, literacy, numeracy, and the other curriculum areas is recommended.

\section{References}

Ability Grouping - State University of New York At Oswego. (n.d.). Retrieved from http://www.oswego.edu/ dparsons/ability_grouping.htm

Anderson, K. M., \& Algozzine, B. Tips for teaching: Differentiating instruction to include all students. Preventing School Failure, 51(3), 49-54.

Barnes, A. C., \& Harlacher, J. E. (2008). Clearing the confusion: Response-to-intervention as a set of principles. Education and Treatment of Children, 31(3), 417-431. http://dx.doi.org/10.1353/etc.0.0000

Basic Facts - $\quad$ Reading Recovery. (2011). Retrieved from http://readingrecovery.org/reading-recovery/teaching-children/basic-facts

Berkeley, S., Bender, W. N., Peaster, L. G., \& Saunders, L. (2009). Implementation of response to intervention a 
snapshot of progress. Journal of Learning Disabilities, 42(1), 85-95. http://dx.doi.org/10.1177/0022219408326214

Bloom, B. (1984). The 2-sigma problem: The search for methods of group instruction as effective as one-to-one tutoring. Educational Researcher, 13, 4-16. http://dx.doi.org/10.3102/0013189X013006004

Bradley, R., Danielson, L., \& Doolittle, J. (2005). Response to intervention. Journal of Learning Disabilities, 38(6), 485-486. http://dx.doi.org/10.1177/00222194050380060201

Assistive Technology for Reading. http://www.wati.org/content/supports/free/pdf/Ch7-Reading.pdf

(n.d.) $\quad$ Retrieved from

Clay, M. M. (1985). The early detection of reading difficulties (3rd ed.). Auckland, New Zealand: Octopus, Heinemann.

Clay, M. (1991). Becoming Literate: The Construction of Inner Control. Heinemann, Auckland.

Cohen, P., Kulik, J. A., \& Kulik, C. C. (1982). Educational outcomes of tutoring: A meta-analysis of findings. American Educational Research Journal, 19, 237-248. http://dx.doi.org/10.3102/00028312019002237

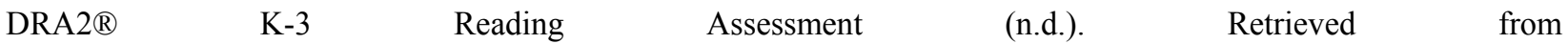
http://www.pearsonglobalschools.com/index.cfm?locator=PS1mIt

Effective approaches to tutoring young readers. (n.d.). Retrieved from http://www.wilder.org/Wilder-Research/Publications/Studies/East\%20Side\%20Learning\%20Center\%20Tutorin g\%20Program/Effective\%20Approaches\%20to\%20Tutoring\%20Young

Elbaum, B., Vaughn, S., Tejero Hughes, M., \& Watson Moody, S. (2000). How effective are one-to-one tutoring programs in reading for elementary students at risk for reading failure? A meta-analysis of the intervention research. Journal of Educational Psychology, 92(4), 605. http://dx.doi.org/10.1037/0022-0663.92.4.605

FCC \& USA v. ABC, Inc. \& Fox Television Stations, Inc., et al. (n.d.). Retrieved from https://www.fcc.gov/document/fcc-usa-v-abc-inc-fox-television-stations-inc-et-al

Fuchs, D., \& Fuchs, L. S. (2006). Introduction to response to intervention: What, why, and how valid is it?. Reading Research Quarterly, 41(1), 93-99. http://dx.doi.org/10.1598/RRQ.41.1.4

How Effective Are One-to-One Tutoring Programs in Reading for ... (n.d.). Retrieved from http://www.parentcenterhub.org/repository/abstract3/

Invernizzi, M., Meir, J., \& Juel, C. (2007). PALS 1-3: Phonological awareness literacy screening 1-3 (6th ed). Charlottesville, VA: University Printing Services.

Invernizzi, M., \& Quellette, M. (2001). Improving Children's Reading Ability Through Volunteer Reading Tutoring Programs. Washington, DC: National governor's association.

Juel, C. (1996). What makes literacy tutoring effective?. Reading Research Quarterly, 31(3), 268-289. http://dx.doi.org/10.1598/RRQ.31.3.3

Juel, C. (1998). What kind of one-on-one tutoring helps a poor reader. Reading and spelling: Development and disorders, 449-471.

Karweit, N. L., \& Wasik, B. A. (1992). A review of the effects of extra-year kindergarten programs and transitional first grades (Report No. CDS-R-41). Washington, DC: Office of Educational Research and Improvement. (ERIC Document Reproduction Service No. ED 357 894)

Kennedy, M. M., Birman, B. F., Demaline, R., \& Moore, M. T. (1987). The effectiveness of Chapter 1 services: second interim report from the National Assessment of. Office of Educational Research and Improvement, US Dept. of Education.

Mack, F. R., Smith, V. G., \& Straight, H. (2010). Response to intervention: Implications for the proficiency of early childhood special educators. The Journal of International Association of Special Education, 11(1), 15-21.

Mastropieri, M. A., \& Scruggs, T. E. (2005). Feasibility and Consequences of Response to Intervention Examination of the Issues and Scientific Evidence as a Model.

McKenzie R. G. (2009). Obscuring vital distinctions: The oversimplification of learning disabilities within RTI. Learning Disability Quarterly, 24, 203-215.

Ministry of Education, Government of the Republic of Trinidad and Tobago, Primary Curriculum Guides (February, 
2014). Retrieved from http://www.drive.google.com/a/moe.edu.tt/

National Institute of Child Health and Human Development. (2000). Report of the National Reading Panel. Teaching children to read: An evidence-based assessment of the scientific research literature on reading and its implications for reading instruction (NIH Publication No. 00-4769). Washington, DC: U.S. Government Printing Office.

National Test, Ministry of Education, Government of the Republic of Trinidad and Tobago, (2013). Retrieved from http://www.moe.gov.tt/student_ntest.html

Put Reading First -- K-3 - US Department of Education. (n.d.). Retrieved from http://incs.ed.gov/publications/html/prfteachers/reading_first1.html

ReadersPreliminaryLookatFactorsAffectingTutoringSuccess.pdf

RTI (Response to Intervention/Instruction) | Stern Center for Language and Learning (n.d.). Retrieved from http://www.sterncenter.org/resources/rti

Sansosti, F. J., Telzrow, C., \& Noltemeyer, A. (2010). Barriers and facilitators to implementing response to intervention in secondary schools: Qualitative perspectives of school psychologists. School Psychology Forum, 4(1), 1-21. N.D.

The influence of the "Response to Intervention" (RTI) program ... (n.d.). Retrieved from http://www.nwmissouri.edu/library/fieldstudies/2012/Dittmer,\%20Rachelle.pdf

Torgesen, J. K., Houston, D. D., Rissman, L. M., Decker, S. M., Roberts, G., Vaughn, S., . . Lesaux, N. (2007). Academic literacy instruction for adolescents: A guidance document from the Center on Instruction. Portsmouth, NH: RMC Research Corporation, Center on Instruction. Retrieved from http://www.centeroninstruction.org/files/Academic\%20Literacy.pdf

Walpole, S., \& McKenna, M.C. (2012). The literacy coach's handbook: A guide to research-based practice (2nd ed.). New York: Guilford Press. New York: Guilford Press.

Wasik, B. A., \& Slavin, R. E. (1993). Reading Research Quarterly, 28, 179-200. http://dx.doi.org/10.2307/747888

\section{Note}

Note 1. UTT providers conduct Professional Development workshops for MOETT teachers during the months of August. 